\title{
Diel cycle of sea spray aerosol concentration over vast areas of the tropical Pacific Ocean and the Caribbean Sea
}

\section{J. Michel Flores ( $\nabla$ flores@weizmann.ac.il )}

Weizmann Institute of Science https://orcid.org/0000-0003-3609-286X

Guillaume Bourdin

University of Maine

\section{Alexander Kostinski}

Michigan Technological University https://orcid.org/0000-0003-1033-615X

\section{Orit Altaratz}

Weizmann Institute of Science

\section{Guy Dagan}

Atmospheric, Oceanic and Planetary Physics, Department of Physics, University of Oxford

\section{Fabien Lombard}

Sorbonne Université https://orcid.org/0000-0002-8626-8782

\section{Nils Haëntjens}

School of Marine Sciences, University of Maine

\section{Emmanuel Boss}

University of Maine

\section{Matthew Sullivan}

The Ohio State University

\section{Gabriel Gorsky}

Observatoire Océanologique de Villefranche

\section{Naama Lang-Yona}

Weizmann Institute of Science https:// orcid.org/0000-0002-2650-2127

\section{Miri Trainic}

Weizmann Institute of Science

\section{Sarah Romac}

CNRS, Station Biologique de Roscoff https://orcid.org/0000-0003-3785-6972

\section{Christian Voolstra}

University of Konstanz https://orcid.org/0000-0003-4555-3795

\section{Yinon Rudich}

Weizmann Institute of Science https://orcid.org/0000-0003-3149-0201

\section{Assaf Vardi}


Weizmann Institute of Science https://orcid.org/0000-0002-7079-0234

\section{llan Koren}

Weizmann Institute of Science https://orcid.org/0000-0001-6759-6265

\section{Article}

Keywords: Sea Spray Aerosol, Diel Cycle, Bubble-bursting Dynamics

Posted Date: September 21st, 2020

DOI: https://doi.org/10.21203/rs.3.rs-74373/v1

License: (c) (1) This work is licensed under a Creative Commons Attribution 4.0 International License. Read Full License

Version of Record: A version of this preprint was published at Nature Communications on September 16th, 2021. See the published version at https://doi.org/10.1038/s41467-021-25579-3. 


\section{Abstract}

Ocean-atmosphere interactions such as sea spray aerosol (SSA) formation have a major role in the climate system, but a global-scale assessment of this micro-scale process is highly challenging. We measured high-resolution temporal patterns of SSA number concentration over the Atlantic Ocean, Caribbean Sea, and the Pacific Ocean covering $42,000 \mathrm{~km}$ of open ocean waters. We discovered a ubiquitous 24-hour rhythm to the number concentration, clearly seen for particle diameters $>\sim 0.58 \mu \mathrm{m}$, with spikes at dawn and drops at dusk throughout the Pacific Ocean and Caribbean Sea, showing more than doubling of the SSA number concentration during the day than at night. No correlation with surface winds, atmospheric radiation, pollution nor oceanic physical properties were found. Instead, parallel diel patterns in particle sizes detected in near-surface waters, attributed to variations in the size of particles smaller than $\sim 1 \mu \mathrm{m}$, point to microbial day-to-night modulation of bubble-bursting dynamics as the cause of the SSA cycle.

\section{Main Text}

Sea spray aerosols (SSA), generated at the ocean surface by wind-driven processes, have a major effect on climate as they impact atmospheric chemistry, Earth's radiative balance, cloud formation and rain properties ${ }^{1-5}$. As ocean waves break, SSA form when bubbles burst and create film and jet droplets ${ }^{6}$. At strong winds (above $\sim 9 \mathrm{~m} \mathrm{~s}^{-1}$ ), spume drops ${ }^{7}$ can be torn off the wave crest. SSA production depends on the physical ${ }^{8}$ and chemical ${ }^{9,10}$ properties of the ocean surface as these, together with wind stress, determine the bubble's bursting dynamics and, therefore, the quantity, size, and composition of the emitted drops. The emitted drops' transport, in turn, depends on the atmospheric marine boundary layer (AMBL) conditions such as the wind, profiles of relative humidity $(\mathrm{RH})$ and temperature, instability, and rain ${ }^{1}$. Understanding the processes that control SSA flux into the atmosphere are essential to better understand the climate system, weather, and accurate ocean-atmosphere models. Yet, these are not well understood ${ }^{2}$, daily patterns, for example, have been only explored with artificial bubbling ${ }^{10,11}$, and globalscale coverage is generally restricted to remote sensing daytime measurements.

In this study, we quantified and explored diurnal patterns of the number concentration of SSA ( $\left.N_{S S A}\right)$ in high spatial and temporal resolution along 42,000 km over the Atlantic Ocean, Caribbean Sea, and Pacific Oceans, measured aboard the schooner Tara during the Tara Pacific Expedition ${ }^{12-14}$. Aerosol size distributions (for optical diameters of $0.25-32 \mu \mathrm{m}$ at $\mathrm{RH}<40 \%$ ) were continuously measured at $27 \mathrm{~m}$ above sea level, along with the spectral particulate absorption and attenuation coefficients $\left(c_{p}\right)$ at $\sim 1.5 \mathrm{~m}$ water depth ${ }^{15}$, as well as AMBL and oceanic (salinity, sea surface temperature, and chlorophyll $a$ ) variables. In addition, aerosols were collected on filters (see Methods for instrumentation details). Tara's route combined sailing periods with days to week-long stops near islands. Here we report the discovery of a distinct 24-hour pattern in $\mathrm{N}_{S S A}$, clearly visible for particles with optical diameters above $\sim 0.58 \mu \mathrm{m}$ $\left(\mathrm{N}_{\mathrm{SSA} \_0.58 \mu \mathrm{m}}\right)$, and a suggested mechanism. The paper is divided as follows: ( $\left.i\right)$ we describe the diel pattern detected in $\mathrm{N}_{\mathrm{SSA} \_0.58 \mu \mathrm{m}}$ and show there are consistently more $\mathrm{N}_{\text {SSA_0.58 } \mu \mathrm{m}}$ at daytime on the vast 
majority of the route. We discuss the origin of the aerosols and their approximate chemical signature; (ii) we explore how atmospheric and oceanic environmental factors affect $\mathrm{N}_{\text {SSA_0.58 } \mu \mathrm{m}}$ and show they are not

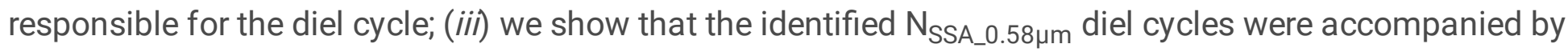
parallel diel patterns of the size of seawater particles; and (iv) we hypothesize that microbial processes at the ocean surface that influence bubble-bursting dynamics are the most probable cause of the observed diel cycle in aerosol number concentration.

\section{Diel pattern in SSA number concentration}

We explored temporal patterns of the number concentration of SSA $\left(\mathrm{N}_{\mathrm{SSA}}\right)$ and found a distinct 24-hour pattern in $\mathrm{N}_{S S A}$, clearly seen for particles with optical diameters above $\sim 0.58 \mu \mathrm{m}\left(\mathrm{N}_{\text {SSA_0.58 } \mu \mathrm{m}}\right.$; Fig. 1 and see Fig. S1 for the diameter determination). We also found day-to-night ratios of $\mathrm{N}_{\mathrm{SSA} \_0.58 \mu \mathrm{m}}>1$ on the vast majority of the route (Fig. 1 and Fig. 2), with an average ratio of $2.3( \pm 0.6)$ over the tropical Pacific Ocean.

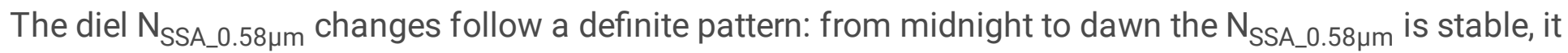
begins rising 06:00 MST (mean solar time; all data was converted from UTC to MST, see Methods), within 30 min after sunrise and begins returning to pre-dawn values at 17:00 MST, with 18:00 MST

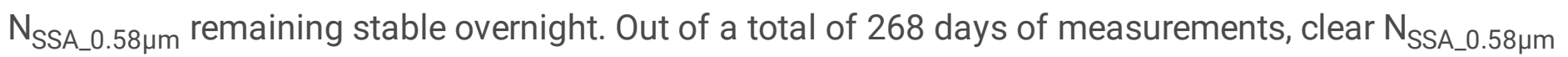
diel cycles (see Methods for the definition) were detected in 143 days, predominantly in the pristine Pacific Ocean and the Caribbean Sea (Fig. 2 and Fig. S2). These cycles had average night (19:00 to 05:00 MST) and day (from 07:00 to 17:00 MST) $\mathrm{N}_{\mathrm{SSA}_{-} 0.58 \mu \mathrm{m}}$ values of $515( \pm 16) \mathrm{L}^{-1}$ and $1282( \pm 34) \mathrm{L}^{-1}$, respectively (Fig. 3A). The hours from 05:00 to 07:00 and from 17:00 to 19:00 were excluded to avoid strong fluctuations of the ratio. The $\mathrm{N}_{\mathrm{SSA} \_0.58 \mu \mathrm{m}}$ diel cycles were identified both while sailing in oligotrophic waters in the open ocean (Fig. 1A) and in island stopovers near coral reefs (Fig. S2 and Fig. S3), suggesting that islands (and Tara's) daily processes do not interfere with the cycles (see Supplementary information S1).

The 58 days where no definite diel cycle was readily apparent (using the strict definition; see Methods for details) in the Pacific Ocean (Fig. S2), still showed higher average daily concentration (784 $\left.\pm 56 \mathrm{~L}^{-1}\right)$ compared to the night values $\left(606 \pm 49 \mathrm{~L}^{-1}\right.$; see Fig. S2A). The $\mathrm{N}_{\text {SSA } \_0.58 \mu \mathrm{m}}$ diel cycle was not detected in the 23 days across the Atlantic Ocean (with $4518( \pm 776) \mathrm{L}^{-1}$ in the daytime and $4553( \pm 357) \mathrm{L}^{-1}$ at night; Fig. S2B), nor in the 9 day leg from Fiji to New Zealand (with $4518( \pm 776) \mathrm{L}^{-1}$ in the daytime and 4553 $( \pm 357) \mathrm{L}^{-1}$ at nighttime; Fig. S2D). Around Japan the cycle was identified only for a few days (Fig. S2C). However, high aerosol concentrations are likely to obscure the diel cycle in those regions. The Atlantic Ocean has generally higher background aerosol concentration 
due to high mineral dust load $(2,11,15)$ and the regions near Japan and New Zealand were highly polluted (11). And, we also found an inverse relationship between the day-to-night ratio of the $\mathrm{N}_{S S A} \_.58 \mu \mathrm{m}$ and the background aerosol concentration (taken as the nighttime concentration; see Fig. S4).

We determined the measured SSA to be of marine origin based on back trajectory analysis and scanning electron microscopy. The calculated back trajectories (using HYSPLIT ${ }^{16,17}$ ) proved that the vast majority of the air masses spent at least 48 hours over the ocean (Fig. 1). In addition, for the period where clear $\mathrm{N}_{\text {SSA_0.58um }}$ diel patterns are seen in the western Pacific (Fig. 1A), we obtained an approximate chemical signature of aerosols collected on filters with average $D>0.58 \mu \mathrm{m}$. We used SEM-EDX analysis and a similar particle classification scheme as described in Laskin et al. ${ }^{18}$ (Fig. 1B; a total of 15.5 days were analyzed between 3 - 17 May, 2017, but for clarity only 11 days are shown. See Table S1 for the other days and Methods for the classification scheme). We found sea salt particles comprised between $50-$ $100 \%$ of the total particles by number. Up to $1000 \mathrm{~km}$ (May 9) away from Keelung, Taiwan, we found a noticeable depletion of chloride (Fig. S5), together with a lower sea salt fraction (50-82\%) and an increase in the presence of other metals (e.g., Al, Si, K, Ca, S) and sulfate. The chlorine depletion and the increase in sulfates suggests that anthropogenic pollutants (e.g., $\mathrm{H}_{2} \mathrm{SO}_{4}, \mathrm{SO}_{2}$ ) were present in the AMBL, as SSA are known to react with them (15). After this period, the sea salt fraction comprised $84-100 \%$ of the total particles by number. Sulfates with no sodium and "Other" species were $<3 \%$ for the whole period. The $\mathrm{N}_{\text {SSA_0.58 } \mu \mathrm{m}}$ diel cycles were also revealed in the filter counts; we counted a total of 4560 particles in 14 daytime filters and 3706 particles in 15 nighttime filters (see Table S1). We have not, however, observed significant day-to-night aerosol-class differences.

\section{Atmospheric and oceanic environmental factors}

The size distribution and number concentration of the bubbles and SSA created by a breaking wave are controlled mainly by the wind speed ${ }^{1}$. We found the $\mathrm{N}_{\mathrm{SSA}-0.58 \mu \mathrm{m}}$ increases with wind speed for both the Pacific and Atlantic Oceans (Fig. 3A and 3B), consistent with previous studies ${ }^{1,2}$. However, the pristine Pacific Ocean daytime $\mathrm{N}_{\mathrm{SSA} \_0.58 \mu \mathrm{m}}$ consistently exceeded the night ones, compared at similar wind speeds (Fig. 3A). Further, wind speed anomalies, for the days the diel cycles were detected, showed no clear diurnal pattern (see Fig. S6). This suggests that the wind is a key player in the process of marine aerosol emission but it doesn't cause the observed diel cycles. Other atmospheric and oceanic environmental factors are known to affect the production and number of SSA, but we found no evidence that they drive the observed $\mathrm{N}_{S S A} 0.58 \mu \mathrm{m}$ diel cycle. Links between the $\mathrm{RH}$, air temperature, and atmospheric stability to the $\mathrm{N}_{\mathrm{SSA}} \mathbf{0 . 5 8 \mu \mathrm { m }}$ diel cycle were explored (see details in the Methods and Fig. S6, Fig. S7, and Fig. S8), and were ruled out as the causes of the $\mathrm{N}_{\text {SSA_0.58 } \mu \mathrm{m}}$ diel pattern. Rain was shown to suppress the $\mathrm{N}_{\text {SSA_0.58um }}$ cycle (Fig. 1A). No link between the intensity of photosynthetically active radiation and the daytime $\mathrm{N}_{\text {SSA_0.58um }}$ was found (Fig. S9). We also discarded secondary organic aerosol production as the cause of the diel cycle since the produced aerosol by this mechanism is much smaller in diameter $(<0.1 \mu \mathrm{m})$. Nor could we find any significant link between physical changes within the AMBL 
and the $\mathrm{N}_{\text {SSA_0.58um }}$ cycle. While there is a diurnal signal in the AMBL height, it has less than $30 \%$ variations ${ }^{19}$ and it cannot account for the variations we see in $\mathrm{N}_{\mathrm{SSA}_{\_} 0.58 \mu \mathrm{m}}$.

Within the ocean surface, changes in salinity and sea surface temperature (SST) can also affect SSA production ${ }^{20}$. However, salinity in the tropics has typical diurnal anomalies of only $0.005 \mathrm{psu}^{21}$, and we did not find strong diurnal salinity changes (Fig. S10). As for SST, even though diurnal variations are known ${ }^{22}$, the rate of temperature change is much weaker and can be observed later in the day ${ }^{22}$ and

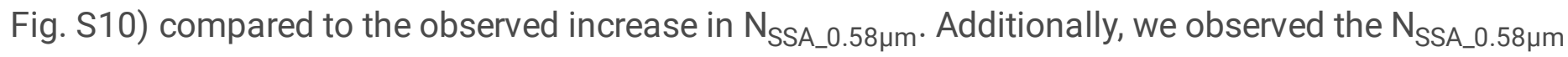
cycle in conditions of wind speeds above $10 \mathrm{~m} \mathrm{~s}^{-1}$ (Fig. 1A and Fig. S8), where SST diurnal changes are expected to be less than $0.25 \mathrm{~K}^{22}$, and in morning overcast conditions (Fig. S8B) when no significant changes in SST are expected. Therefore, we can conclude that neither salinity nor SST cause the $\mathrm{N}_{\text {SSA_0.58um }}$ cycles.

These findings suggest that neither atmospheric nor oceanic environmental factors can explain the

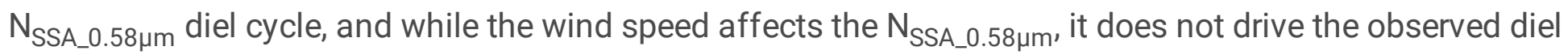

cycles. Furthermore, the presence of the $\mathrm{N}_{S S A}{ }_{-0.58 \mu \mathrm{m}}$ diel cycle in the presence of anthropogenic pollutants and in clean conditions (Fig. 1A,B and Fig. S5), implies anthropogenic and continental sources are also not the cause. This suggests that the diel cycle may be triggered by changes in the ocean surface itself.

\section{Diel patterns in the size of seawater particles}

The identified $\mathrm{N}_{\text {SSA_0.58um }}$ diel cycles in the lower atmosphere were accompanied by distinct diel cycles in the measurements of near-surface ocean light attenuation wavelength dependence of $c_{p}$ (expressed as particle size index $r$, Fig. 1C). The index is found via a power-law fit to the wavelength-dependent $c_{p}{ }^{23,24}$.

$$
c_{p}=c_{p}\left(\lambda_{0}\right)\left(\frac{\lambda}{\lambda_{0}}\right)^{-\gamma}
$$

where $c_{p}\left(\lambda_{0}\right)$ is $\mathrm{c}_{p}$ at a reference wavelength $\lambda_{0}$ and $\gamma$ is the spectral slope of $\mathrm{c}_{p}$. Variability of $\gamma$ indicates changes in the median particle size and is most sensitive to particles in the range of $0.22-20 \mu \mathrm{m} 23,25$, with smaller $y$ associated with larger median particle size (similar to the Ångström exponent for aerosols). Figure $1 \mathrm{C}$ shows that the $\mathrm{N}_{\text {SSA_0.58um }}$ diel cycle correlates well with the values of $\gamma$. Note that $\gamma$

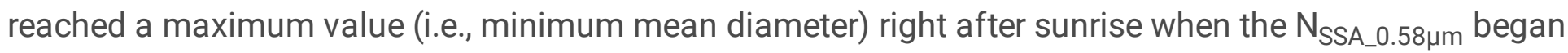
to increase, and a minimum value (i.e., maximum mean diameter) before sunset when $\mathrm{N}_{\text {SSA_0.58 } \mu \mathrm{m}}$ were decreasing (Fig. 1C). We, therefore, calculated the rate of change of $\gamma\left(\partial \gamma / \partial \mathrm{t}\left(\mathrm{hr}^{-1}\right)\right.$; see Methods) for concurrent days (92 days in total) where a $\mathrm{N}_{\mathrm{SSA}_{-} 0.58 \mu \mathrm{m}}$ diel cycle was also detected (Fig. 4A,B). We found a parallel behavior, with a continuous decrease in the mean particle diameter at nighttime $\left(\partial \gamma / \partial \mathrm{t}\left(\mathrm{hr}^{-1}\right)>\right.$

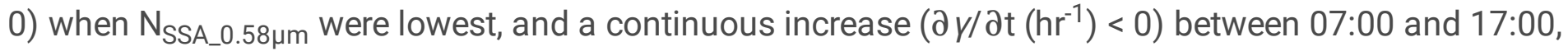


when $\mathrm{N}_{\text {SSA_0.58um }}$ were highest. In the Pacific Ocean, where the $\mathrm{N}_{\text {SSA_0.58um }}$ diel cycles occurred, most $Y$ values were above 0.8 (Fig. S11A) reaching 1.4 and having a strong latitudinal dependence (Fig. S11B). In the Fiji to New Zealand leg, $y$ values were around 1.0, but no cycle was detected (Fig. S11C). In the Atlantic Ocean, though there were diel cycles in $\gamma$ (Fig. S11A), its values were below 0.8, indicating a larger mean particle size and thereby suggesting the presence of larger planktonic species than in the Pacific Ocean.

Similar diel cycles of $y$ in the open ocean have been previously documented in ${ }^{24-26}$. Changes in $y$ can be attributed to several factors: cell growth, division, and aggregation, selective changes in particle size or concentration due to a balance between primary production and loss due to grazing and viral pressure, or changes in the refractive index of the cell population, which is related to their carbon content. In the Equatorial Pacific such changes were attributed primarily to phytoplankton growth and division ${ }^{27}$. During daytime cells photosynthesize, fix inorganic carbon and accumulate carbohydrates and lipids which are respired during the night ${ }^{28}$, subsequently cells will generally divide. We found the daytime increase is associated with cell growth or aggregation of pico-phytoplanktonic populations, as the $y$ changes measured during $\mathrm{N}_{\mathrm{SSA} \_0.58 \mu \mathrm{m}}$ diel cycles (in the western Pacific) can be attributed to variations in size of particles smaller than $\sim 1 \mu \mathrm{m}$ (see Methods and Fig. S12), and we also see a daily increase in particulate organic carbon (Fig. S10A). The decrease in mean size at night can be due to selective grazing, cell division or virus-induced lysis 29,30 .

\section{Mechanism hypothesis}

Areas with high chl-a concentrations showed the lowest day-to-night $\mathrm{N}_{\mathrm{SSA} \_0.58 \mu \mathrm{m}}$ ratios, and the $\mathrm{N}_{\text {SSA_0.58um }}$ diel cycles were mainly observed in areas with low chl-a (Fig. 2). These oceanic oligotrophic regions are typically dominated by cyanobacteria ${ }^{31,32}$.

During photosynthesis eukaryotic phytoplankton and cyanobacteria can secrete extracellular polymeric substances (EPS). EPS are a diverse array of large molecules which forms a major component of the dissolved organic carbon pool in the ocean, and have been implicated in the formation of biofilms and marine snow ${ }^{33}$. Recently, in a different context, EPS released by bacteria were observed to increase bubble lifetime, thereby dramatically decreasing their film thickness, and yielding more numerous and transportable droplets at burst than those produced by clean bubbles (see Fig. 1 in ${ }^{34}$ ). These new findings are essential as SSA formation is directly related to film drops formed by the fragmentation of the thin fluid cap film ${ }^{35}$.

Consequently, we conjecture that the diel changes in the $\mathrm{N}_{S S A} 0.58 \mu \mathrm{m}$ are controlled by microbial processes in the ocean surface. Such processes whether at the near-surface water-AMBL interface, or in the upper several meters of the ocean through bubble scavenging of the excreted EPS from bacteria, may affect bubble bursting dynamics, changing the number and size of the emitted droplets and therefore 


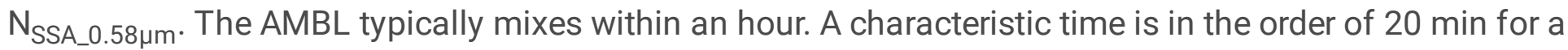
$500 \mathrm{~m}$ AMBL (1). Hence, significant changes in the production of droplets can be expected to happen within a similar timeframe in which we observed the transient increase of $\mathrm{N}_{\text {SSA_0.58um. }}$. Although we do not pinpoint a direct role of marine bacteria affecting bubble-bursting dynamics in the open ocean surface, recent studies have shown a possible role for bacteria modulating ocean surface properties 33,36-39 and bubble-bursting dynamics ${ }^{34,40,41}$.

We presented in-situ evidence that the number concentration of SSA with optical diameter D > 0.58 $\mu \mathrm{m}$ (at $\mathrm{RH}<40 \%$ ) have distinct 24-hour cycles over oligotrophic waters, with an average of $2.3 \pm 0.6$ times higher number concentrations during daytime than at night. Our results show inverse correlation between the ambient aerosol concentration and the magnitude of the observed cycle, suggesting that over areas with high aerosol concentration (e.g., with a strong contribution from long range transport of continental aerosol) the cycle is present but masked. Additionally, the gradual emergence of the diel cycle for larger diameters (Fig. S1) suggests that the longer lifetimes of smaller aerosols (the lifetime of aerosols is inversely proportional to their size) also contributes to masking the cycle, particularly for the small sizes. While it is known that SSA formation originates from the interaction of wind and waves, with bulk oceanic properties (i.e., SST, salinity, chl-a) affecting it (2), here we show that there is a concomitant daily mechanism that modulates aerosol concentration in a 24-hour rhythm. While we do not provide (or possess) direct measurements of near-surface water microbial processes, the parallel increase of the mean particle size within the ocean surface during the day, driven by photosynthetic growth and secretion of extracellular polymeric substances, points towards a possible link between microbial processes at the ocean surface and the $\mathrm{N}_{\text {SSA_0.58um }}$ cycle.

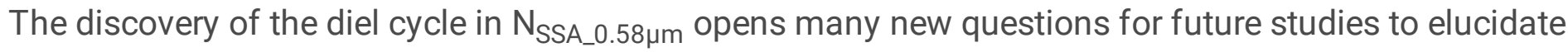
the mechanism underlining this phenomenon and the direct impact of marine biological processes on the physical properties of the surface ocean, and the link to aerosol fluxes and properties. Moreover, on a larger scale, the connection to cloud and rain properties and consequently energy fluxes and climate.

\section{Methods}

\section{Schooner Tara}

Measurements were conducted aboard the R/V Tara during the first year of the Tara Pacific expedition 12-14. The R/V Tara is a $36 \mathrm{~m}$ long, $10 \mathrm{~m}$ wide aluminum hull schooner with two $27 \mathrm{~m}$ long masts, equipped with a meteorological station (Station Bathos II, Météo France) measuring air temperature, relative humidity, and pressure. The station is located on the stern around $7 \mathrm{~m}$ above sea level, the wind speed and direction are measured at the top of the mast, $\sim 27 \mathrm{~m}$ above sea level (asl), and a thermosalinometer (Sea-Bird Electronics SBE45 MicroTSG) measures sea surface temperature (SST) and salinity with its main water entrance located about $0.5-3 \mathrm{~m}$ under the sea surface (depending on ocean 
conditions). The intensity of Photosynthetically Active Radiation (PAR; wavelengths between 400 and 700 $\mathrm{nm}$ ) was measured next to the meteorological station by a QCR-2150 (Biospherical Instruments Inc.). The meteorological station recorded frequencies are listed in Table S2. The SST and salinity were measured at $0.1 \mathrm{~Hz}$ and processed to $1 \mathrm{~min}$ averages. The PAR is analyzed to $1 \mathrm{~min}$ average of $1 \mathrm{~Hz}$ measurements.

\section{Continuous aerosol instrumentation and inlet}

A detailed description of the aerosol instrumentation during the expedition can be found in Flores et al. $2020^{14}$. In short, an optical particle counter (OPC; EDM-180 GRIMM Aerosol Technik Ainring GmbH \& Co. KG, Ainring, Germany), for continuous aerosol size distribution measurements (from $0.25-32 \mu \mathrm{m}$, sorted into 31 bins), and a custom-made aerosol filter system consisting of four $47 \mathrm{~mm}$ filter holders and one vacuum pump (Diaphragm pump ME 16 NT, VACUUBRAND BmbH \& Co KG, Wertheim, Germany) were installed aboard R/V Tara. Two separate inlets, located next to each other, were constructed out of conductive tubing of $1.9 \mathrm{~cm}$ inner diameter and a funnel (allowing the collection of all diameters) and mounted on the rear backstay of Tara. For the Atlantic Ocean measurements, from Lorient, France to Miami, U.S.A., the inlet was installed half way up the backstay $(\sim 15 \mathrm{~m}$ asl) and after Miami, the inlet was relocated to the top of the backstay ( 27m asl).

The OPC measures single particles at $683 \mathrm{~nm}$ and it was calibrated at the refractive index of polystyrene latex spheres. It collects the scattered light using a wide-angle collector optic at a mean scattering angle of $90^{\circ}$; the optical design smoothes out Mie scattering resonances and reduces the sensitivity to particle shape. A Nafion dryer was installed before the OPC, which reduced the sampled air relative humidity to below $40 \%{ }^{14}$. The flow through the OPC was 1.2 liters per minute and it produced a particle size distribution every 60 seconds.

The filters from the custom-made system were changed, in general, twice a day, collecting aerosols for periods of at least 12 hours. The filter holder for the analysis presented here contained $0.8 \mu \mathrm{m}$ polycarbonate filters (ATTP04700, Millipore) that were stored at room temperature in PetriSlide dishes preloaded with absorbent pads (Millipore, PDMA04700) to keep the filters dry while stored. The flow through the filter was 30 litter per minute for the filters analyzed here.

\section{Continuous water measurements}

The R/V Tara was equipped with an ocean surface flow-through autonomous sampling system, similar to the one installed during the Tara Oceans Expeditions, to measure sea surface physical and bio-optical properties as described in ${ }^{15}$. The inline system consisted of a Sea-Bird Electronics SBE45 MicroTSG for measurements of sea surface temperature (SST) and salinity and an AC-S spectrophotometer (WET Labs, 
Inc.) measuring hyperspectral particulate absorption $\left(a_{\mathrm{p}}\right)$ and particulate attenuation $\left(\mathrm{c}_{p}\right)$ with $\mathrm{a} \sim 4 \mathrm{~nm}$ resolution, and an ECO-BB3 (WetLabs Inc.) set in a BB-box of $\sim 4.5 \mathrm{~L}$ measuring particulate backscattering at three wavelength $(470 \mathrm{~nm}, 532 \mathrm{~nm}$ and $650 \mathrm{~nm})$, altogether mounted in an autonomous setup described in Dall'Olmo et al. ${ }^{42}$ and Slade et al. ${ }^{26}$. The size range of the measured particles is $>0.2 \mu \mathrm{m}$, but contribution of particles $>20 \mu \mathrm{m}$ is assumed negligible. Particulate Organic Carbon (POC) concentrations were computed from $c_{p}{ }^{43}$ and chlorophyll-a concentrations were estimated from the particulate absorption line height ${ }^{15}$. Additionally, a particle size index $(\gamma)$, an estimate of the mean particle size in the ocean near-surface waters, was calculated using the wavelength-dependency of $\mathrm{c}_{p}$ and that its spectral shape can be approximated as a power law (see main text).

\section{Air mass back trajectory analysis}

The presented 48 hours back trajectories in Fig. 1 were calculated using the NOAA's HYSPLIT atmospheric transport and dispersion model ${ }^{16,17}$. They represent the average trajectories of the 'Ensemble option' that were calculated based on an endpoint at $250 \mathrm{~m}$ height. We chose the 'Ensemble option' to have a better representation of where the air masses were coming from. We did not use a lower starting height as the minimum height for the optimal configuration of the ensemble is $250 \mathrm{~m}$.

\section{Diameter determination of the diurnal cycle}

To obtain an estimation for the minimal diameter impacted by the changes in the diurnal emission, we analyzed each bin from the OPC. We took the data only in the Pacific Ocean and when Tara was at least $100 \mathrm{~km}$ away from land (islands included). The OPC has 31 bins for measurements between 0.25 to 32 $\mu \mathrm{m}$, in Fig. $\mathrm{S} 1$ we show the box plot analyses for 16 bins from the OPC, up to $3.0 \mu \mathrm{m}$. Fig. $\mathrm{S} 1$ shows there is no diurnal difference for the diameters below $0.58 \mu \mathrm{m}$, whereas, for larger diameters the cycle is clear. However, there is an exponential decrease in concentration from the smaller diameter channels to the $0.58-0.65 \mu \mathrm{m}$ channel, suggesting the diel cycle might be masked in the smaller diameters due to higher concentrations.

\section{Definition of the diel cycle}

First, all the data was converted to mean solar time (MST) using the equation:

$$
M S T=U T C+\operatorname{Lon} \frac{1}{360}
$$


where UTC is the Coordinated universal time, and Lon is the longitude in degrees (west $<0$, east $>0$ ). MST assumes there is no day to day variation in the UTC of solar noon at a location, and for our dataset it is a good assumption, mainly since the majority of measurements were taken along the tropics.

Each $24 \mathrm{~h}$ period was analyzed independently. For a day to be considered to have a diel cycle an increase in concentration had to be observed between 06:00 and 07:00 and a decrease after 17:00, with a greater $\mathrm{N}_{\text {SSA_0.58um }}$ observed during daytime (see above for the diameter determination) during daytime. For this, we divided the day into four periods, from 00:00 to 05:00 (dawn), 07:00 to 11:59 (morning), 12:00 to 17:00 (afternoon) and from 19:00 to 23:59 (night). The counts (per fixed liter volume) measured by the particle counter can be assumed to follow a Poisson distribution, therefore their standard deviation is , where $\mu$ is the mean. Hence, for a day to be considered to have a diel cycle the two following conditions had to be met:

$\mu_{\text {morning }}>\mu_{\text {dawn }}+\sigma_{\text {dawn }}$ and $\mu_{\text {night }}<\mu_{\text {afternoon }}-\sigma_{\text {afternoon }}$

Figure S2 shows the places where the diel cycle was detected using this definition.

\section{Chlorophyll-a along Tara's route}

The chlorophyll-a concentration along Tara's route was calculated using the AC-S ${ }^{15}$ and to approximate the chl-a concentrations when the AC-S was not functioning, we used the level 3 SNPP-VIIRS satellite monthly data maps. For each month, we used Tara's hourly location to first extract a $0.2 \times 0.2$ degree area for each point, then this area was averaged to get a corresponding chl-a concentration at each point. Finally, a 24-hour average was taken along Tara's route. Figure 2B shows the satellite calculated chl-a concentration, and the in situ chl-a inferred from AC-S measurements.

\section{Daytime and nighttime SSA $_{\underline{0.58}} \underline{\underline{m}}$ concentration vs Wind speed}

In order to understand the role of wind speed in the $\mathrm{N}_{\text {SSA_0.58 } \mu \mathrm{m}}$ cycle, we separated the Pacific data (for days when a cycle was detected) into daytime (07:00 - 17:00) and nighttime (19:00 - 05:00) periods, and binned the total aerosol counts of $D>0.58 \mu \mathrm{m}$ into $2 \mathrm{~m} \mathrm{~s}^{-1}$ bins (Fig. 3a; data within $100 \mathrm{~km}$ from continental coasts and Japan was not used to avoid pollution artifacts). There were between 3612 to 23136 events per bin used. The Atlantic Ocean data was binned into $4 \mathrm{~m} \mathrm{~s}^{-1}$ bins for comparison. There were between 949 to 5056 events per bin used. 


\section{Rate of change of $\gamma(\underline{\partial} y / \partial \mathrm{t})$.}

As mentioned above, $\gamma$ is an indicator of the size distribution among particles ( $<20 \mu \mathrm{m}$ in diameter) in the ocean surface. From Fig. 1 we see $y$ decrease at daytime (i.e. the sizes of the plankton increase) and increase over nighttime. To quantify the intensity and timing of this change over a full day, we calculated the rate of change of $\gamma$. First, to fill in data gaps that correspond to periods when the AC-S was measuring filtered seawater for calibration purposes (normally shorter than 30 minutes), we did a linear interpolation. Data gaps larger than 30 minutes were not interpolated. Then, each continuous segment was smoothed applying a low-pass digital filter with a pass band frequency of 18 hours. Then the rate of change $\partial y / \partial t\left(\mathrm{hr}^{-1}\right)$ was calculated. Finally, Fig. 4B shows a box plot analysis of the days where a $\mathrm{N}_{\mathrm{SSA} \_0.58 \mu \mathrm{m}}$ diel cycle was found and there was at least 23 hours of the AC-S data.

\section{Diurnal cycle near Niue Island when Tara was anchored}

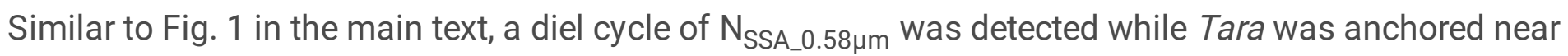
Niue Island $\left(19^{\circ} 03^{\prime} 14^{\prime \prime} \mathrm{S} 169^{\circ} 55^{\prime} 12^{\prime \prime} \mathrm{W}\right)$. Figure S3 shows a diurnal cycle of $\gamma$, increasing during nighttime (smaller particle mean diameter) and decreasing during daytime (bigger particle mean diameter).

\section{Box plot analysis for three different legs}

Similar to the analysis shown in Fig. 3, we performed box plot analysis for the days the cycle was not detected in the Pacific Ocean (Fig. S4A), for the Atlantic Ocean transect (Fig. S4B), for the tour around Japan (Fig. S4C), and for the Fiji - New Zealand leg (Fig. S4D). In the Atlantic Ocean average counts of $4518( \pm 776) \mathrm{L}^{-1}$ in the daytime and $4553( \pm 357) \mathrm{L}^{-1}$ at nighttime were measured. For the Fiji $-\mathrm{New}$ Zealand leg average counts of $1388( \pm 352) \mathrm{L}^{-1}$ during daytime and $1352( \pm 85) \mathrm{L}^{-1}$ at nighttime were measured.

\section{Day to nighttime ratio vs. aerosol concentration}

To explore the relationship between the diel cycles and the aerosol concentration, we quantified the day to nighttime concentration ratio for $D>0.58 \mu \mathrm{m}$ vs. the total (using all the bins from the OPC) nighttime aerosol concentration. For this purpose, after converting the data to mean solar time and taking every 24hour period as independent, we first averaged the total nighttime concentration (from 19:00 to 05:00), next we took a 5-day running average, and finally the data was binned into equally number bins from low to high concentration. A 5-day running average was also taken for the day to nighttime ratio. Figure S4 
shows the inverse relationship between the day to nighttime concentration ratio and the aerosol loading. The analysis was also done using the daytime and a $24 \mathrm{hr}$ concentration average, no significant difference was found.

\section{Scanning electron microscope with Energy disperse X-ray analysis}

Using Scanning Electron Microscopy with energy-disperse X-ray analysis (SEM-EDX) and a similar particle classification scheme as described in Laskin et al. $(2012)^{18}$, we classified each particle into one of five major classes of aerosols: i) Sea salt. [Na] greater than all other elements detected (except $\mathrm{Cl}$ ); ii) Metals with $\mathrm{Na}$ : [Na] present but [Na] < [Al, Si, K, Ca, S]; iii) Sulfate/SeaSalt. [Na] > [Al, Si, K, Ca] but [Na] < [S]; iv) Sulfates: [Na] 0 and [S]>0; and v) Other. all remaining particles.

To perform the SEM-EDS analysis, we used a Zeiss Sigma500 SEM with a Bruker XFlash ${ }^{\circledR}-6 \mid 60$ Quantax EDS detector, and the Bruker ESPRIT feature software package for automatic particle detection and chemical classification in EDS.

The SEM was set at a working distance of about $7.5 \mathrm{~mm}( \pm 0.1)$, an accelerating voltage of $8.0 \mathrm{kV}$, an aperture size of $60 \mu \mathrm{m}$, and a magnification of 2000 . The backscatter detector was used to acquire the images. For each filter four images, covering a total of $2471 \mu \mathrm{m}^{2}$ surface area, were taken and each particle above a minimum area of $0.08 \mu \mathrm{m}^{2}$ was counted and an EDS spectrum acquired. After the acquisition of the images and EDS spectra, we took only the particles that had an average diameter greater than $0.58 \mu \mathrm{m}$ and for each of their corresponding EDS spectra, the method described in ${ }^{44}$ was used to calculate the mass percent of each detected element. We excluded $C$ from the mass percent calculation since the filters were made of polycarbonate. Following the mass calculation, particles containing sodium above 0.01 mass percent $([\mathrm{Na}]>0)$ were first separated from those without sodium. The $\mathrm{Na}$ containing particles with more sodium than any other detected element (besides $\mathrm{Cl}$ ) were denoted "Sea-salt". The rest of $\mathrm{Na}$ containing particles were subdivided into two classes: "Metals with $\mathrm{Na}$ " if [Na] < [Al], [Ca], [K], [Si], and mixed "SeaSalt/Sulfate" - if [Na] > [Al], [Ca], [K], [Si] [Na] but [Na] < [S]. The sodiumfree particles were assigned to two classes: "Sulfate" if [S] $>0$ and "Other" for the remaining particles. A total of 14339 particles, where 8266 had average $D \geq 0.58 \mu \mathrm{m}$, were analyzed. In the 14 daytime filters (for the period between 4 May and 17 May, 2017; see Table S1) we counted a total of 7247 particles and 4560 with $D \geq 0.58 \mu \mathrm{m}$. In the 15 nighttime ones we counted a total of 5894 particles and 3706 with $D \geq$ $0.58 \mu \mathrm{m}$. We had between 80 to 781 particles per filter.

Figure S5A shows the $\mathrm{SSA}_{0.58 \mu \mathrm{m}}$ counts per litter calculated using the SEM images (particle count and area imaged) and the total air sampled. Figure 5SB shows histograms of the chlorine mass percentage found in the particles per filter. Between May 4 and May 9 we see a noticeable $\mathrm{Cl}$ depletion, suggesting the atmospheric marine boundary layer in this region had anthropogenic pollutants. 


\section{Atmospheric Diurnal anomalies}

We calculated diurnal anomalies for the air temperature, relative humidity $\left(\mathrm{RH}_{7 \mathrm{~m}}\right)$, and wind speed $\left(\mathrm{U}_{27 \mathrm{~m}}\right)$, in the Pacific Ocean for two scenarios: 1) the days where a diel cycle in $\mathrm{N}_{\text {SSA_0.58 } \mu \mathrm{m}}$ was detected and 2) when there was no diel cycle in $\mathrm{N}_{\mathrm{SSA}_{-} 0.58 \mu \mathrm{m}}$ (Fig. S6). The average between midnight and 05:00 is the baseline for each variable. To avoid continental influence, this analysis was done only in the open ocean and near the Pacific islands except Japan and Fiji.

The air temperature and relative humidity anomalies show no discernible differences between days where a cycle was detected (Fig S6; panels AirT_a, RH_a) and when there was no cycle (FigS6; panels AirT_b, $\left.\mathrm{RH} \_b\right)$. This implies that even though both atmospheric variables have a diurnal signature, their changes, especially in relative humidity, cannot explain the diurnal patterns seen for $\mathrm{N}_{\text {SSA_0.58um }}$.

Finally, the wind speed anomaly analysis (Fig. S6, WS_a, WS_b) also does not show sharp changes at sunrise or sunset; there might be isolated cases, but no consistent pattern.

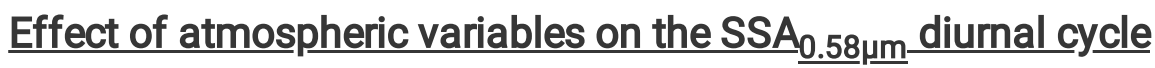

Rain, relative humidity, air temperature, and atmospheric instability can have an effect on the production, growth, transport and removal of SSA. Here we explain why these variables do not explain the $\mathrm{N}_{\text {SSA_0.58um }}$ diel cycle.

First, rain suppressed the $\mathrm{N}_{\text {SSA_0.58um }}$ cycle (Fig. 1A and Fig. S5A), as it is a known washout mechanism of aerosols. Second, there are several indications against $\mathrm{RH}$ as a major driving factor underlying the detected diurnal cycle in $\mathrm{SSA}_{0.58 \mu \mathrm{m}}$ concentration. For example, for a given SSA, its dry diameter is around $1 / 4$ of its diameter at formation (1). Hence, if $\mathrm{RH}$ variations were the cause, we expect to see the diurnal patterns in all sizes, and especially at smaller diameters, but this is not the case (Fig. S1). Additionally, the $\mathrm{N}_{\text {SSA_0.58um }}$ diel cycles were observed in days with and without daily variations in air temperature and $\mathrm{RH}$ (Fig. S7). In addition, $\mathrm{RH}$ and air temperature diurnal anomalies have similar trends for days when the NSSA_0.58um diel cycles was observed and when it was not (Fig. S6). Finally, the atmospheric stability that influences the transport of aerosols from the ocean surface upward does not explain the diurnal cycle either. Firstly, under most atmospheric conditions, concentrations of SSA with $D_{\text {dry }}<10 \mu \mathrm{m}$ are well mixed in the marine boundary layer, showing little variation with height (1), hence a

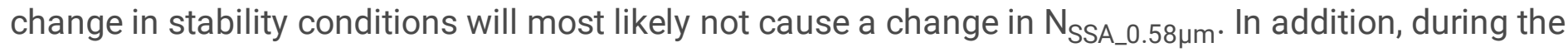
Taiwan - Fiji transect, the cycle appeared in three distinct atmospheric states: with clear skies at low wind speeds, with overcast conditions and with trade cumulus throughout the day (see Fig. S8). Especially, that a cycle is observed even if the morning is overcast (Fig. S8b), and that there are cycles when there is no air temperature variability (Fig. S7), infers that most likely atmospheric stability does not 
play a significant role in the observed diel cycles. Therefore, we conclude that the atmospheric variables cannot explain the observed $\mathrm{N}_{\text {SSA_0.58um }}$ diel cycle.

\section{Photosynthetically active radiation (PAR) vs daytime to nighttime ratio of concentration}

By definition, solar radiation drives diurnal cycles. Therefore, we explored links between the intensity of solar radiation, measured by the average daytime photosynthetically available radiation (PAR), and the average daytime number count of $\mathrm{SSA}_{0.58 \mu \mathrm{m}}$ to determine if the intensity of solar radiation has a measurable effect on the total amount of $\mathrm{SSA}_{0.58 \mu \mathrm{m}}$. We considered the nighttime (background) concentration by calculating the ratio of daytime to nighttime number concentration for the same day and plotted it against the average PAR (Fig. S9). No clear correlation between PAR and NSSA_0.58um was

found. Furthermore, examples of days with similar PAR that showed different daytime $\mathrm{N}_{S S A} \_.58 \mu \mathrm{m}$ can be seen in Fig. 1B and Fig. S8. This analysis suggests the $\mathrm{N}_{\text {SSA_0.58 } \mu \mathrm{m}}$ diel cycle is not caused directly by changes in solar radiation, but that there is a parallel mechanism.

\section{Surface Ocean variables anomalies}

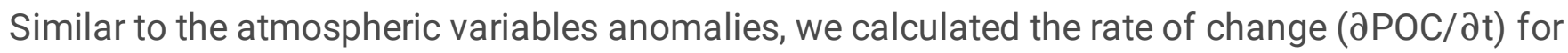
particulate organic carbon (POC) and diurnal anomalies for chlorophyll a, salinity, and SST for days where the cycle was detected and not in the Pacific Ocean (Fig. S10). The average between midnight and 05:00 is the baseline for each variable. To avoid continental influence, this analysis was done only in the open ocean and near the Pacific islands except Japan and Fiji.

The $\mathrm{Chl} a$ and salinity anomalies analysis does not show any diurnal changes. The POC shows a decrease during nighttime and an increase during daytime both when we detected a $\mathrm{N}_{S S_{-} \_.58 \mu m}$ diel cycle and when we did not. The daytime increase in POC can be attributed to photosynthetic growth or particle aggregation. Similarly, in the SST anomaly, for both cases, when cycles were detected (Fig. S10, SST_a) and not detected (Fig. S10, SST_b), we see a diurnal signature. However, here we see no difference from the base line up to 09:00, and only a gradual increase from 10:00. Depending on wind conditions, there can be a few degrees difference between SST at the skin of the ocean surface and SST at 0.5-3m depth, and expect to have a stronger diurnal cycle near the skin of the ocean (18), but we don't expect to have a sharp change at sunrise or sunset.

\section{Particle size index $y$ in different parts of the ocean}

To understand the differences in $y$ and how it might be related to $S_{S A} A_{0.58 \mu m}$ production, we calculated the average $y$ in 24 hour cycles. Figure S11 shows three different scenarios: Fig. S11A shows the average $y$ 
measured in the Atlantic Ocean and in the Pacific Ocean when diurnal cycles in $\mathrm{N}_{\text {SSA_0.58um }}$ were detected. Fig. S11B shows the average $y$ measured during the Keelung - Fiji leg separated by different latitude ranges and the average $y$ while Tara was anchored near Niue Island. Finally, Fig. S11C shows the average $y$ measured in the transect from Fiji to New Zealand. This shows the latitudinal dependence of $y$ at low latitudes and that in the Atlantic Ocean there is a larger mean particle size, which suggest the presence of larger planktonic species than in the Pacific Ocean.

\section{Contribution of small, $\sim<1 \mu \mathrm{m}$ particles, to $\gamma$ variations}

In order to estimate what are the daytime $y$ changes associated with, we calculated the contribution of small particles to the size changes observed in $\gamma$. To do so, we calculated the backscattering $\left(b_{b p}\right)$ to total particulate scattering $\left(b_{p}\right)$ ratio $\left(b_{b p}: b_{p}\right)$ at $\lambda=532 \mathrm{~nm}$.

$$
b_{b p}: b_{p}(\lambda)=\frac{b_{b p}(\lambda)}{c_{p}(\lambda)-a_{p}(\lambda)}
$$

where $c_{p}$ is the particulate attenuation and $a_{p}$ the particulate absorption. Since smaller particles have a higher $b_{b p}: b_{p}$, the $b_{b p}: b_{p}$ can serve as a proxy for the contribution of small ( $\sim 1 \mu \mathrm{m}$ particles) to the bulk particle size index $\gamma$ variation. $b_{b p}: b_{p}$ and $\gamma$ can be taken as two independent variables since the former is the ratio of the amplitudes of the backscattering and the total scattering at a single wavelength (here 532 $\mathrm{nm})$, while the latter refers to the spectral shape of $c_{p}$.

Since the $b_{b p}$ measurements with the ECO-BB3 sensor have low signal to noise ratio due to its sensitivity to bubble in the water line and accumulation of particles in the sensor, the $b_{b p}: b_{p}$ was first averaged for one hour periods and then smoothen with a five hour moving average. Figure S12A shows the cooccurrence of a diel cycle in $y$ and the $b_{b p}: b_{p}$ in the western Pacific Ocean between $15^{\circ} \mathrm{N} 137^{\circ} \mathrm{E}$ and $17.6^{\circ} \mathrm{S} 177.4^{\circ} \mathrm{E}$. where diel cycles in $\mathrm{N}_{\mathrm{SSA} \_} 0.58 \mu \mathrm{m}$ were also observed. Twardowski et al. ${ }^{45}$ showed that while for $\gamma<0.8$ the backscattering ratio is mostly affected by changes in refractive index of particles, for $y>0.8$ the size of particles become a major contributor to the backscattering ratio. Therefore, the observation of a diel cycle of the backscattering ratio synchronized with $y$ and daylight in these oligotrophic waters, suggests that the diel cycle in ocean particle size is mainly due to changes in size of pico-phytoplanktonic populations. Pronounced diel cycles of pico-phytoplanktonic populations (e.g., cyanobacteria) in the Equatorial Pacific, have been previously shown 27,46,47.

Figure S12B shows the same as Fig. S12A, but for the Fiji - New Zealand leg. Here we do not observe diel

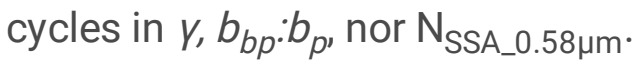

\section{Declarations}


Acknowledgments

Special thanks of gratitude to the R/V Tara crew. The authors will like thank the Tara Pacific Coordinators for their valuable comments on the manuscript.

Funding: This research was supported by a research grant from Scott Jordan and Gina Valdez, the De Botton for Marine Science, the Yeda-Sela center for Basic research, and a research grant from the Yotam Project.

We are keen to thank the commitment of the following institutions for their financial and scientific support that made this unique Tara Pacific expedition possible: CNRS, PSL, CSM, EPHE, Genoscope/CEA, Inserm, Université Côte d'Azur, ANR, agnès b., UNESCO-IOC, the Veolia Environment Foundation, Région Bretagne, Serge Ferrari, Billerudkorsnas, Amerisource Bergen Company, Lorient Agglomeration, Oceans by Disney, the Prince Albert II de Monaco Foundation, L'Oréal, Biotherm, France Collectivités, Kankyo Station, Fonds Français pour l'Environnement Mondial (FFEM), Etienne BOURGOIS, the Tara Foundation teams and crew. Tara Pacific would not exist without the continuous support of the participating institutes. The authors also particularly thank Serge Planes, Denis Allemand and the Tara Pacific consortium.

Partial support was provided by NSF AGS-1639868. This study has been conducted using E.U. Copernicus Marine Service Information and Mercator Ocean products. GD is supported by the European Research Council (ERC) project constRaining the EffeCts of Aerosols on Precipitation (RECAP) under the European Union's Horizon 2020 research and innovation programme with grant agreement No 724602 . FL is supported by Sorbonne Université, Institut Universitaire de France and the Fondation CA-PCA. The inline and atmospheric optics dataset was collected and analyzed with support from NASA Ocean Biology and Biogeochemistry program under grants NNX13AE58G and NNX15AC08G to U. of Maine. This is publication number \# 13 of the Tara Pacific Consortium.

\section{Author Contributions}

Conceptualization, J.M.F, O.A., A.K., M.T., E.B., F.L., G.G., Y.R., A.V., and I. K.; Data curation, J.M.F., G.B., N. H., E. B., and F.L.; Formal analysis, J.M.F lead, G.B., G.D., N. H., and F.L. supporting; Funding acquisition, E.B., F.L., G.G., A.V., and I. K.; Investigation, J.M.F., G.B. N.H., N.L.-Y., and F.L.; Project administration, J.M.F., G.B., M.T., E.B., F.L., G.G., A.V., and I.K.; Supervision, J.M.F., E.B., F.L., G.G., Y.R., A.V., and I.K.; Visualization, J.M.F., A.V., and I.K.; Writing - Original Draft, J.M.F.; Writing - Review \& Editing, J.M.F, A.K., O.A., I.K., and A.V. lead, G.B., G.D., N. H, M.S.B., N.L.-Y., M.T., E.M., F.L., G.G., Y.R. supporting.

\section{Competing Interests.}

Authors declare no competing interests.

\section{References}


1. Lewis, R. \& Schwartz, E. in Geophysical Monograph Series (American Geophysical Union, 2004). doi:10.1029/GM152

2. De Leeuw, G. et al. in Ocean-Atmosphere Interactions of Gases and Particles (eds. Liss, P. S. \& Johnson, M. T.) 171-246 (Springer Berlin Heidelberg, 2014). doi:10.1007/978-3-642-25643-1_4

3. Textor, C. et al. Analysis and quantification of the diversities of aerosol life cycles within AeroCom. Atmospheric Chemistry and Physics 6, 1777-1813 (2006).

4. Gantt, B. et al. Global distribution and climate forcing of marine organic aerosol - Part 2: Effects on cloud properties and radiative forcing. Atmospheric Chemistry and Physics 12, 6555-6563 (2012).

5. McCoy, D. T. et al. Natural aerosols explain seasonal and spatial patterns of Southern Ocean cloud albedo. Science Advances 1, e1500157 (2015).

6. Wu, J. Evidence of sea spray produced by bursting bubbles. Science 212, 324-326 (1981).

7. Monahan, E. C., Spiel, D. E. \& Davidson, K. L. in Oceanic Whitecaps (eds. Monahan, E. C. \& Niocaill, G. M.) 167-174 (Springer Netherlands, 1986). doi:10.1007/978-94-009-4668-2_16

8. Salter, M. E. et al. An empirically derived inorganic sea spray source function incorporating sea surface temperature. Atmospheric Chemistry and Physics 15, 11047-11066 (2015).

9. Modini, R. L., Russell, L. M., Deane, G. B. \& Stokes, M. D. Effect of soluble surfactant on bubble persistence and bubble-produced aerosol particles. J. Geophys. Res. Atmos. 118, 1388-1400 (2013).

10. Long, M. S. et al. Light-enhanced primary marine aerosol production from biologically productive seawater. Geophys. Res. Lett. 41, 2661-2670 (2014).

11. Keene, W. C. et al. Factors that modulate properties of primary marine aerosol generated from ambient seawater on ships at sea. J. Geophys. Res. Atmos. 122, 11,961-11,990 (2017).

12. Planes, S. et al. The Tara Pacific expedition-A pan-ecosystemic approach of the "-omics" complexity of coral reef holobionts across the Pacific Ocean. PLoS Biol 17, e3000483 (2019).

13. Gorsky, G. et al. Expanding Tara Oceans Protocols for Underway, Ecosystemic Sampling of the Ocean-Atmosphere Interface During Tara Pacific Expedition (2016-2018). Frontiers in Marine Science 6, (2019).

14. Flores, J. et al. Tara Pacific Expedition's Atmospheric Measurements of Marine Aerosols across the Atlantic and Pacific Oceans: Overview and Preliminary Results. Bulletin of the American Meteorological Society 101, E536-E554 (2020).

15. Boss, E. et al. The characteristics of particulate absorption, scattering and attenuation coefficients in the surface ocean; Contribution of the Tara Oceans expedition. Methods in Oceanography 7, 52-62 (2013).

16. Stein, A. F. et al. Noaa's HYSPLIT atmospheric transport and dispersion modeling system. Bulletin of the American Meteorological Society 96, 2059-2077 (2015).

17. Rolph, G., Stein, A. \& Stunder, B. Real-time Environmental Applications and Display sYstem: READY. Environmental Modelling \& Software 95, 210-228 (2017). 
18. Laskin, A. et al. Tropospheric chemistry of internally mixed sea salt and organic particles: Surprising reactivity of $\mathrm{NaCl}$ with weak organic acids. J. Geophys. Res. 117, (2012).

19. Ho, S., Peng, L., Anthes, R. A., Kuo, Y.-H. \& Lin, H.-C. Marine boundary layer heights and their Iongitudinal, diurnal, and interseasonal variability in the southeastern pacific using COSMIC, CALIOP, and radiosonde data. J Clim 28, 2856-2872 (2015).

20. De Leeuw, G. et al. Production flux of sea spray aerosol. Reviews of Geophysics 49, (2011).

21. Drushka, K., Gille, S. T. \& Sprintall, J. The diurnal salinity cycle in the tropics. Journal of Geophysical Research: Oceans 119, 5874-5890 (2014).

22. Kawai, Y. \& Wada, A. Diurnal sea surface temperature variation and its impact on the atmosphere and ocean: A review. Journal of Oceanography 63, 721-744 (2007).

23. Boss, E., Twardowski, M. S. \& Herring, S. Shape of the particulate beam attenuation spectrum and its inversion to obtain the shape of the particulate size distribution. Appl Opt 40, 4885 (2001).

24. Dall'Olmo, G. et al. Inferring phytoplankton carbon and eco-physiological rates from diel cycles of spectral particulate beam-attenuation coefficient. Biogeosciences 8, 3423-3439 (2011).

25. Boss, E., Haëntjens, N., Westberry, T. K., Karp-Boss, L. \& Slade, W. H. Validation of the particle size distribution obtained with the laser in-situ scattering and transmission (LISST) meter in flow-through mode. Opt Express 26, 11125-11136 (2018).

26. Slade, W. H. et al. Underway and moored methods for improving accuracy in measurement of spectral particulate absorption and attenuation. J. Atmos. Oceanic Technol. 27, 1733-1746 (2010).

27. Durand, M. D. \& Olson, R. J. Contributions of phytoplankton light scattering and cell concentration changes to diel variations in beam attenuation in the equatorial Pacific from flow cytometric measurements of pico-, ultra- and nanoplankton. Deep Sea Research Part II: Topical Studies in Oceanography 43, 891-906 (1996).

28. Becker, K. W. et al. Daily changes in phytoplankton lipidomes reveal mechanisms of energy storage in the open ocean. Nat Commun 9, 5179 (2018).

29. Cullen, J. J., Lewis, M. R., Davis, C. O. \& Barber, R. T. Photosynthetic characteristics and estimated growth rates indicate grazing is the proximate control of primary production in the equatorial Pacific. J. Geophys. Res. 97, 639 (1992).

30. Stramski, D. \& Reynolds, R. A. Diel variations in the optical properties of a marine diatom. Limnology and Oceanography Letters 38, 1347-1364 (1993).

31. Bidigare, R. R. \& Ondrusek, M. E. Spatial and temporal variability of phytoplankton pigment distributions in the central equatorial Pacific Ocean. Deep Sea Research Part II: Topical Studies in Oceanography 43, 809-833 (1996).

32. Ras, J., Claustre, H. \& Uitz, J. Spatial variability of phytoplankton pigment distributions in the Subtropical South Pacific Ocean: comparison between in situ and predicted data. Biogeosciences 5, 353-369 (2008). 
33. Decho, A. W. \& Gutierrez, T. Microbial extracellular polymeric substances (epss) in ocean systems. Front Microbio/ 8, 922 (2017).

34. Poulain, S. \& Bourouiba, L. Biosurfactants Change the Thinning of Contaminated Bubbles at Bacteria-Laden Water Interfaces. Phys Rev Lett 121, 204502 (2018).

35. Wang, X. et al. The role of jet and film drops in controlling the mixing state of submicron sea spray aerosol particles. Proc Natl Acad Sci U S A 114, 6978-6983 (2017).

36. Ottesen, E. A. et al. Ocean microbes. Multispecies diel transcriptional oscillations in open ocean heterotrophic bacterial assemblages. Science 345, 207-212 (2014).

37. Iuculano, F., Mazuecos, I. P., Reche, I. \& Agustí, S. Prochlorococcus as a possible source for transparent exopolymer particles (TEP). Front Microbio/ 8, 709 (2017).

38. Kurata, N. et al. Surfactant-associated bacteria in the near-surface layer of the ocean. Sci. Rep. 6, 19123 (2016).

39. Ribalet, F. et al. Light-driven synchrony of Prochlorococcus growth and mortality in the subtropical Pacific gyre. Proc Natl Acad Sci U S A 112, 8008-8012 (2015).

40. Poulain, S., Villermaux, E. \& Bourouiba, L. Ageing and burst of surface bubbles. J Fluid Mech 851, 636-671 (2018).

41. Poulain, S. \& Bourouiba, L. Disease transmission via drops and bubbles. Phys Today 72, 70-71 (2019).

42. Dall'Olmo, G., Westberry, T. K., Behrenfeld, M. J., Boss, E. \& Slade, W. H. Significant contribution of large particles to optical backscattering in the open ocean. Biogeosciences 6, 947-967 (2009).

43. Gardner, W. D., Mishonov, A. V. \& Richardson, M. J. Global POC concentrations from in-situ and satellite data. Deep Sea Research Part II: Topical Studies in Oceanography 53, 718-740 (2006).

44. Salge, T., Neumann, R., Andersson, C. \& Patzschke, M. Advanced mineral classification using feature analysis and spectrum imaging with EDS. Proceedings: International Mining Congress and Exhibition, 23rd, Turkey, UCTEA Chamber of Mining Engineers of Turkey 357

45. Twardowski, M. S. et al. A model for estimating bulk refractive index from the optical backscattering ratio and the implications for understanding particle composition in case I and case II waters. J. Geophys. Res. 106, 14129-14142 (2001).

46. Vaulot, D. \& Marie, D. Diel variability of photosynthetic picoplankton in the equatorial Pacific. J. Geophys. Res. 104, 3297-3310 (1999).

47. Binder, B. J. \& DuRand, M. D. Diel cycles in surface waters of the equatorial Pacific. Deep Sea Research Part II: Topical Studies in Oceanography 49, 2601-2617 (2002).

\section{Figures}



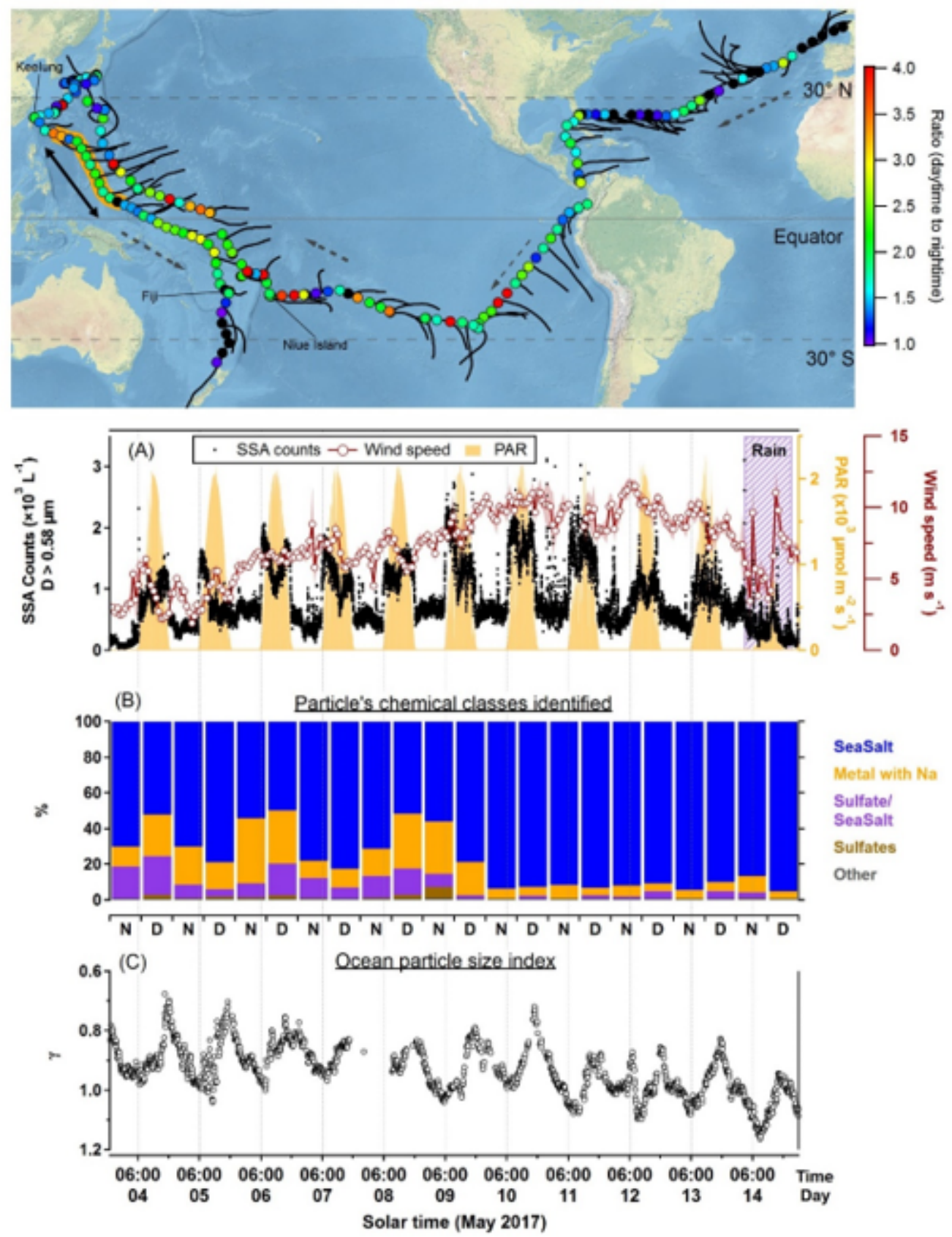

Figure 1

24-hour cycle of aerosol concentration and marine particle size index. Top panel: Map of R/V Tara's route, with dotted arrows along the sailing direction and solid black lines along the 48 hour back-trajectories. Filled circles on the route are colored by the value of day-to-night concentration ratio. The data in panels (a) through (c) are from the orange-shaded transect in the western Pacific between Keelung and Fiji (next to the double ended arrow). (A) Main observation. Aerosol concentration per liter (Ddry $>0.58 \mu \mathrm{m}$, collected $27 \mathrm{~m}$ above sea surface), superimposed on the 24-hour beat of incoming solar flux as represented by the photo-synthetically active radiation (PAR). Time series are punctuated by abrupt spikes at dawn and drops at dusk. The diel rhythm (away from land) is evident, ubiquitous and persists on cloudy days. Pollution origin of this cycle is ruled out by the 48 hour back-trajectories; (B) Aerosol composition determined by SEM-EDX for $\mathrm{D}>0.58 \mu \mathrm{m}$. " $\mathrm{N}$ " and " $\mathrm{D}$ " denote night and day, respectively. 
This is compelling evidence for the marine origin of the aerosols. The collection filters were replaced at about 08:00-09:30 and 20:00-21:30 (see Table S1 in the SI for timing details); (C) 24-hour signal of marine particle size index $y$ (vertical axis inverted). Particles grow during the day and shrink during the night. Data collected at $0.5-3 \mathrm{~m}$ below sea surface. Note: The designations employed and the presentation of the material on this map do not imply the expression of any opinion whatsoever on the part of Research Square concerning the legal status of any country, territory, city or area or of its authorities, or concerning the delimitation of its frontiers or boundaries. This map has been provided by the authors.
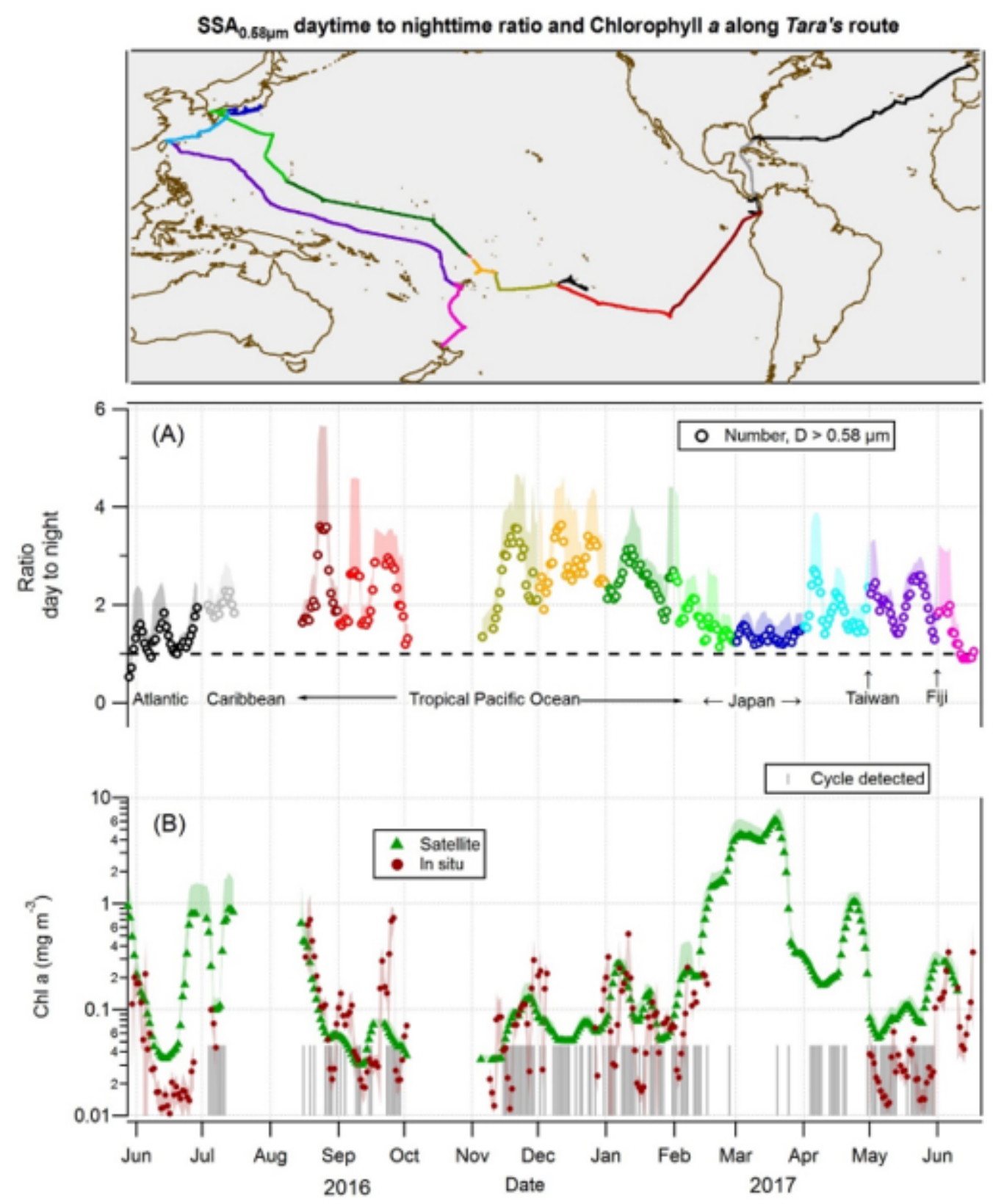

Figure 2

Day-to-night NSSA_0.58um ratio and chlorophyll a concentration along R/V Tara's route. Top panel: Tara's route, color-coded by month; (A) The ratio of day to night concentration of SSA with $D \geq 0.58 \mu \mathrm{m}$. The colors as defined in the map; (B) a 5-day running average of Chlorophyll-a concentration measured with the AC-S aboard Tara (red circles) and calculated using satellite data (green triangles; see methods), with 
the shaded area outlining the standard deviation. The largest day-to-night ratios are in areas with low chla concentration, i.e., in oligotrophic ("blue") waters. Note: The designations employed and the presentation of the material on this map do not imply the expression of any opinion whatsoever on the part of Research Square concerning the legal status of any country, territory, city or area or of its authorities, or concerning the delimitation of its frontiers or boundaries. This map has been provided by the authors.
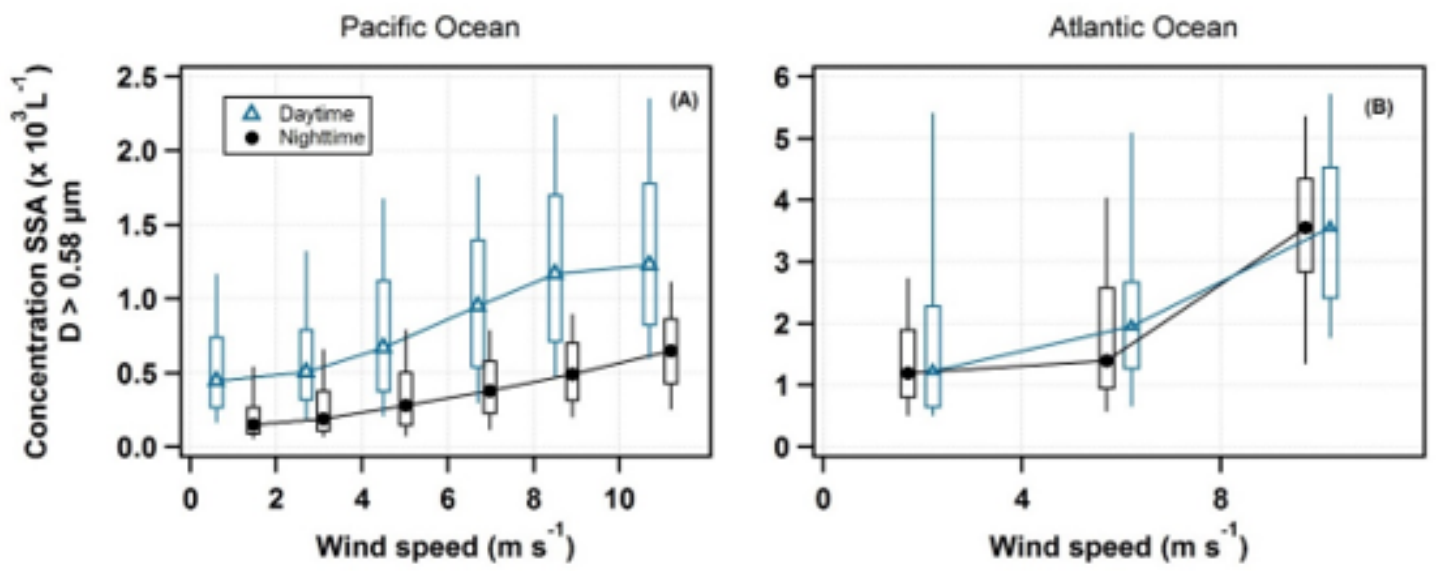

Figure 3

Dependence of NSSA_0.58 $\mu \mathrm{m}$ on wind speed. Box plots of the NSSA_0.58 $\mu \mathrm{m}$ vs. wind speed, binned at 2 ms-1 for the Pacific Ocean (panel A) and by 4 ms-1 for the Atlantic Ocean (panel B) where data collected further than $100 \mathrm{~km}$ away from land was used. The day and night data are offset for clarity. The y-axis scale is different for the two panels. While the expected increase of aerosol concentration with wind speed is indeed observed, no relation between the 24-hour cycle and wind speed is found. 
Diurnal changes of $\mathrm{SSA}_{0.58 \mu \mathrm{m}}$ and $\hat{\partial} / \hat{t} \mathrm{t}$
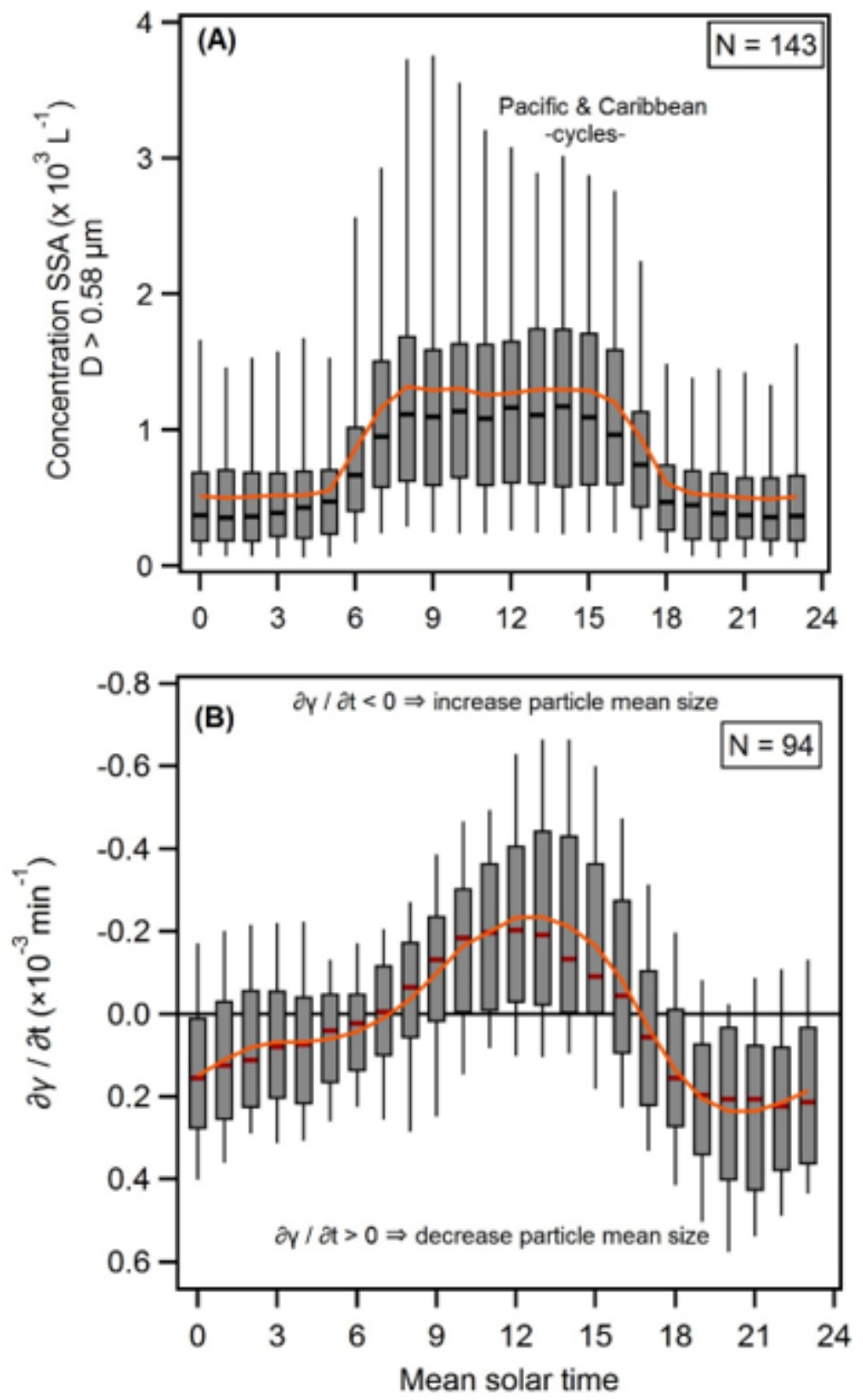

\section{Figure 4}

Day-to-night changes of NSSA_0.58 $\mu \mathrm{m}$ and $\partial \gamma / \partial \mathrm{t}(\mathrm{hr}-1)$ where an NSSA_0.58 $\mu \mathrm{m}$ diel cycle was evident. (A) Box plot analysis of the 143 days with the 24-hour cycle in Pacific Ocean shows compelling statistical significance of day and night counts; (B) Box plot analysis of the $y$ rate of change for the 94 days where a diel cycle of NSSA_0.58 $\mu \mathrm{m}$ occurred (vertical axis inverted). Statistically significant day to night variation is readily discernible. The box plots show the median, and the 5th, 25th, 75th, and 95th percentiles; the orange line is the average.

\section{Supplementary Files}


This is a list of supplementary files associated with this preprint. Click to download.

- SIFloresetalComm.docx 